\title{
Selected Area XPS Analysis for Identification of Pigment Compounds in Microscopic Paint Flakes
}

\author{
Bryony Joanne James, ${ }^{1}$ Rebecca Cameron, ${ }^{2}$ and Camilla Baskcomb ${ }^{2}$ \\ ${ }^{1}$ Department of Chemical and Materials Engineering, University of Auckland, Private Bag 92019, 1142 Auckland, New Zealand \\ ${ }^{2}$ Auckland Art Gallery Toi o Tāmaki, P.O. Box 5449, Auckland, New Zealand
}

Correspondence should be addressed to Bryony Joanne James, b.james@auckland.ac.nz

Received 9 March 2008; Accepted 6 May 2008

Recommended by Vladimir Tsukruk

The application of X-ray photoelectron spectroscopy to the analysis of paint flakes from a painting by Henry Fuseli (1741-1825) is presented. Historically, the application of XPS to art conservation and restoration studies has been limited by the poor spatial resolution of the technique. Presented here is the successful analysis of paint flakes in the order of $100 \mu \mathrm{m}$ using "imaging" XPS in conjunction with selected area analysis. Raman microscopy failed to satisfactorily identify the compounds present in this instance, and energy dispersive spectroscopy could not differentiate between lead and sulphur (two of the elements of interest) due to the limited energy resolution inherent in that technique. Using XPS analysis of the lead $4 \mathrm{f}$ peak revealed that the pigment was a leadbased pigment, in this case comprising exclusively lead-sulphur compounds.

Copyright (C) 2008 Bryony Joanne James et al. This is an open access article distributed under the Creative Commons Attribution License, which permits unrestricted use, distribution, and reproduction in any medium, provided the original work is properly cited.

\section{INTRODUCTION}

A large variety of materials characterization techniques are employed in the field of cultural heritage conservation. In the study of paintings, spectroscopic techniques are frequently used to identify the composition of pigments, ground, and support for the purposes of restoration and conservation. The most commonly used of the spectroscopic techniques are Fourier transform infrared spectroscopy (FTIR) $[1,2]$ and Raman spectroscopy [3-5], usually used in conjunction with light microscopy these techniques offer good spatial resolution, can analyse small samples, and can be used in situ. X-ray fluorescence (XRF) is also commonly used and requires only a minute amount of sample $[6,7]$. Additional techniques include, but are not limited to, Xray emission spectroscopy, Mossbauer spectroscopy and gas chromatography-mass spectrometry (GC-MS). The techniques are complimentary with some better suited to organic materials, others to inorganics, excellent reviews of the common spectroscopy techniques are given by Bitossi et al. [8] and Dawson [9]. Each technique has its own spatial resolution in both $X-Y$ and $Z$ axes, thus determining the "surface sensitivity" and lateral resolution of the resulting analysis area. Naturally, in situ nondestructive techniques are the most desirable but when that is not possible then techniques that use extremely small sample size (in the order of $\mu \mathrm{m}$ ) are the next best option.

One technique that has great potential for analysis of pigments, particularly inorganic pigments, is X-ray photoelectron spectroscopy (XPS). XPS is an information dense technique giving a semiquantified elemental analysis of the top ten or so atomic layers of a solid sample. Chemical functionality can also be determined by examining the energy shifts in the spectrum for individual elements. However, recently XPS has found limited application in conservation studies due to the limited spatial resolution in the XY plane. Where XPS has been used, it has been on samples that are sufficiently large and homogenous that this limited spatial resolution has not been an issue [10]. Recent advances in XPS instrumentation have now made it possible to analyse small samples with improved spatial resolution and to make use of the so-called "imaging" XPS, where energies can be imaged with a spatial resolution of down to $3 \mu \mathrm{m}$. This paper presents the results of analysis of a pigment flake, approximately $100 \mu \mathrm{m}$, across exploiting imaging XPS and selected area analysis.

The painting in question was a watercolour drawing on paper by Henry Fuseli, The Great Father and Ancient Night (c.1810),held in the collection of the Auckland Art Gallery. This particular work was of interest due the curious dark 
appearance of certain parts of the image, suggesting that the pigment may have originally been lighter. Artists of this period had limited pigments available to them and of the whites both lead sulphate and lead carbonate are notoriously unstable. In the presence of atmospheric sulphur, these can darken to lead sulphide, therefore, dramatically altering the appearance of a picture. Only very small samples of paint were available for analysis and attempts were made to confirm the identity of the pigment compounds using Raman spectroscopy and energy dispersive spectroscopy (EDS) but without conclusive results. Fourier transform infrared (FTIR) analysis was considered but would have required a larger sample than could be taken from this delicate work. XPS analysis was used in this instance attempting to confirm the suspected identity of the lead compounds.

\section{EXPERIMENTAL}

Areas for sampling were chosen so as to be inconspicuous and were recorded on a photograph of the original work, as shown in Figure 1. The paint flakes were collected from the painting using two fine scalpel blades with 40x magnification under a binocular microscope. The samples were stored on a glass microscope slide, and as the flakes were too small to handle and mount in any other way, they were analysed in situ on the slide.

The Raman spectra were recorded on a Renishaw 1000 Raman imaging microscope using a Renishaw solid-state diode laser as an excitation source emitting a line in the near-infrared region at $\sim 785 \mathrm{~nm}$ at $26 \mathrm{~mW}$ with a grating of 1200 lines $/ \mathrm{mm}$. A 20x objective was used which focused the beam to a size of approximately $5 \mu \mathrm{m}$ at the sample surface. EDS analysis was conducted using an EDAX Phoenix EDS detector attached to an FEI Quanta 200 Scanning electron microscope.

XPS analysis was conducted using a Kratos Axis Ultra DLD XPS. A magnifying video camera was used to locate a paint flake in the approximate analysis area. Lens and iris settings of the XPS were selected to give an analysis area of $400 \mu \mathrm{m}$ square. Monochromatic aluminium $\mathrm{K} \alpha \mathrm{X}$ rays (energy $1486.69 \mathrm{eV}$ ) at a power of $150 \mathrm{~W}$ were used in conjunction with a detector pass energy of $160 \mathrm{eV}$ in order to collect an image centred on the energy of the lead $4 \mathrm{f}$ peak (approximately $139 \mathrm{eV}$ ). A charge neutralization system was optimised to ensure that any shift in the energy of the lead $4 \mathrm{f}$ peak was the result of chemical functionality, not sample charging. Any sample charging that did occur was accounted for by shifting all the peaks with respect to the carbon $1 \mathrm{~s}$ peak $(285 \mathrm{eV})$.

Once a paint flake had been located, the lens and iris settings of the instrument were changed to generate selected areas for analysis (in the Kratos instrument, the X-rays are still used as a spatially diffuse "flood" source and the analysis area is selected from within that area by electron optics). These analysis areas were $300 \mu \mathrm{m} \times 500 \mu \mathrm{m}$ (for survey scans) and $110 \mu \mathrm{m}$ diameter (for narrow scans or individual elements) centred on the flake already identified in imaging mode. As the flakes were in the order of $100 \mu \mathrm{m}$, this had the

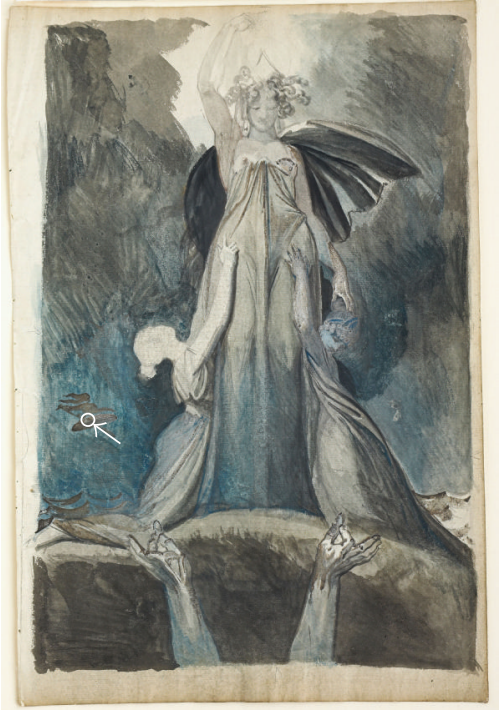

(a)

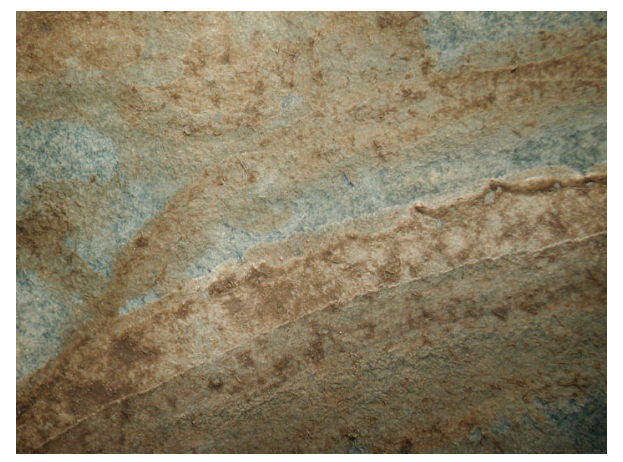

(b)

Figure 1: (a) The Great Father and Ancient Night, Auckland Art Gallery Toi o Tāmaki purchased 1965 (1965/73). Arrow indicates sample area. (b) Detail of sample area x6.4 magnification.

inevitable consequence of including some of the glass slide in the analysis area, whilst smaller selected areas are possible, they were not necessary in this instance as the elements of interest were not detected in the glass slide. The larger analysis areas also improved the signal to noise ratio of the spectra.

Survey scans were conducted from $1100 \mathrm{eV}$ to $0 \mathrm{eV}$ with a step size of $1 \mathrm{eV}$, a dwell time of 180 milliseconds (for 20 sweeps, giving total acquisition time of 3964 seconds), and a detector pass energy of $160 \mathrm{eV}$ in order to determine what elements were present. Narrow scans were performed on the carbon $1 \mathrm{~s}$ peak, centred on $285 \mathrm{eV}$ and used as an internal standard for charge referencing and also on the lead $4 \mathrm{f}$ peak. The step size for the narrow scans was $0.1 \mathrm{eV}$, dwell time was around 300 milliseconds, and pass energy of the detector was set to $40 \mathrm{eV}$. For the carbon 20 sweeps were conducted for a total acquisition time of 1206 seconds. For the lead a total of 30 sweeps were conducted for a total acquisition time of 1810 seconds. 


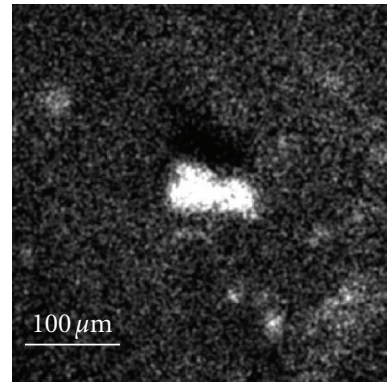

(a)

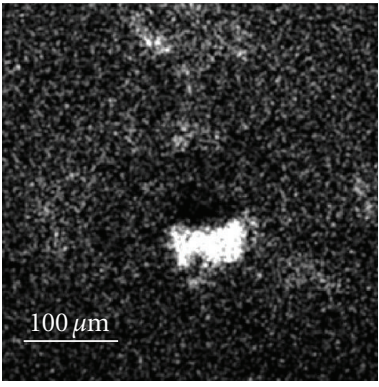

(b)
FIGURE 2: XPS image captured at $138 \mathrm{eV}$ to show presence of lead.

Wide scans were quantified using a Shirley background. Narrow scans were deconvoluted using a Shirley background and Gaussian-Lorentzian peak shape with a G-L ratio of 70.

\section{RESULTS AND DISCUSSION}

The results of EDS analysis indicated the presence of lead and carbon though the presence of any sulphur were masked by the peak overlap between the sulphur and lead peaks. The Raman spectrum for a white area of a paint fragment gave bands at $1155,977,640,607,449$, and $438 \mathrm{~cm}^{-1}$ characteristic of Anglesite or lead sulphate $\left(\mathrm{PbSO}_{4}\right)$. However, the spectrum of the dark area in the paint fragment exhibited fluorescence which masked the bands. Only two weak bands were observed at $975 \mathrm{~cm}^{-1}$ and $1306 \mathrm{~cm}^{-1}$, indicating either that an impurity was present or that the lead sulphate had changed composition.

The results of XPS imaging of the energy of the lead $4 \mathrm{f}$ peak are shown in Figure 2. As may be seen, the flakes were apparent as brighter areas (where lead is present) and were of the order of $100 \mu \mathrm{m}$ across. Survey scans were conducted to detect all the elements present (excluding hydrogen which cannot be detected by XPS) and a typical result is given in Table 1. It must be noted that the analysis area used for survey scans $(300 \mu \mathrm{m} \times 500 \mu \mathrm{m})$ was substantially larger than the paint flake and as such included the glass slide. This was not a problem as the aim of the survey scans was to identify the presence or otherwise of lead, iron, and sulphur (elements not present in the glass slide) in order to determine the appropriate narrow scans for chemical state analysis.

The semiquantification of the elements in the survey scans was dominated by the contribution from the glass slide; however, lead and sulphur were detected, whereas iron was not (one of the possible pigments in the dark areas was iron gall).

The lead $4 \mathrm{f}$ peak is naturally shaped as a "doublet" (i.e., has two main peaks separated by $4.7 \mathrm{eV}$ ). In this case, each of the two halves of the doublet was further made up of separate peaks arising from the various chemical states of lead that were present. As shown in Figure 3, each half of the lead doublet could be deconvoluted into 3 peaks. The energies of these peaks (charge referenced to hydrocarbon at $285 \mathrm{eV}$ ), and their relative amounts, correspond to the chemical states summarised in Table 2.
TABle 1: Sem-quantified elemental composition (note excludes hydrogen).

\begin{tabular}{lcc}
\hline & Atomic \% & Mass \% \\
\hline Sodium & 7.7 & 9.7 \\
Oxygen & 42.7 & 37.7 \\
Calcium & 0.5 & 1.2 \\
Carbon & 35.2 & 23.3 \\
Chlorine & 0.4 & 0.8 \\
Sulphur & 0.2 & 0.4 \\
Lead & 0.7 & 7.8 \\
Silicon & 11.3 & 17.5 \\
Magnesium & 1.3 & 1.8 \\
\hline
\end{tabular}

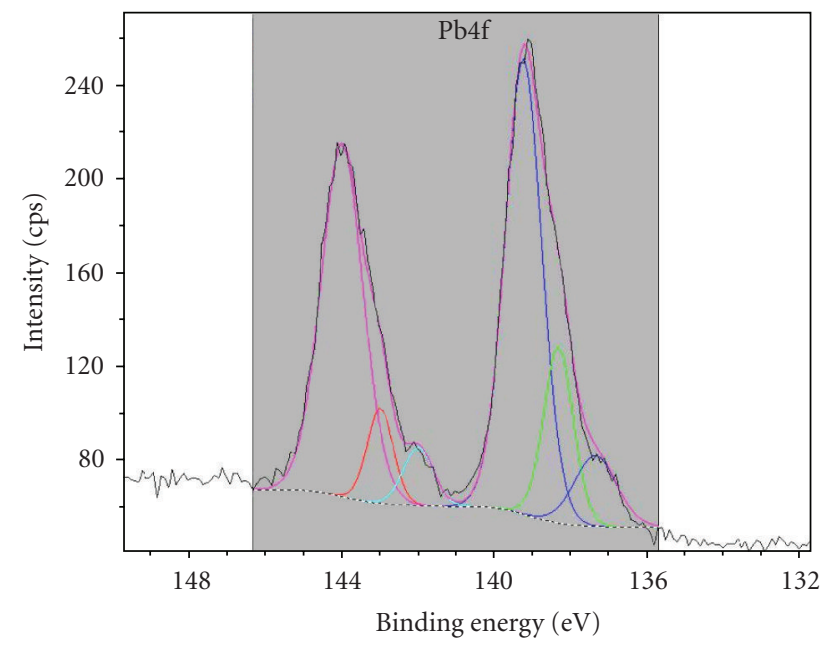

FIGURE 3: Lead $4 \mathrm{f}$ peak deconvoluted with 3 constituent peaks per half.

TABLE 2: Lead $4 \mathrm{f}$ binding energies, chemical state, and quantification.

\begin{tabular}{lcc}
\hline Energy (doublet) eV & Chemical state & Relative amount \\
\hline $137.3(142.0)$ & $\mathrm{PbO}$ or $\mathrm{PbS}[11]$ & $10.8 \%$ \\
$138.3(143.0)$ & $\mathrm{PbSO}_{3}[12]$ & $17.4 \%$ \\
$139.3(144.0)$ & $\mathrm{PbSO}_{4}[12]$ & $71.8 \%$ \\
\hline
\end{tabular}

The majority of the lead appears to be present as lead sulphate $\left(\mathrm{PbSO}_{4}\right)$, in agreement with the Raman result, with some present as lead sulphite $\left(\mathrm{PbSO}_{3}\right)$ and some present either as lead sulphide (PbS) or lead (II) oxide (PbO). As both lead sulphate and sulphite are usually white and lead (II) oxide is red or yellow, it seems likely that the peak at $137.3 \mathrm{eV}$ is a result of lead sulphide due to the black colour in these areas.

\section{CONCLUSIONS}

Using XPS, with imaging mode and selected area analysis, it has been possible to analyse flakes of paint that are in the order of $100 \mu \mathrm{m}$ across. Whilst Raman spectroscopy was able to identify the areas of the paint that were not 
darkened, in the darkened region fluorescence prevented a reliable identification. EDS analysis of the paint fragments was compromised by energy resolution and peak overlap of the lead and sulphur peaks. Not only was XPS able to confirm the presence of lead and sulphur in the flakes of pigment in this case, it was also possible to identify the lead compounds present. In particular, confirming the presence of $\mathrm{PbS}$ suggests that there might have been some atmospheric degradation of the white pigment compounds.

Whilst XPS should in no way be considered a replacement for the range of spectroscopic techniques usually employed by art conservators and restorers, it is a useful addition to the tools available. Only with the advent of selected area analysis and imaging XPS systems, can the small samples usually available in such circumstances be successfully analysed.

\section{REFERENCES}

[1] M. Odlyha, "Investigation of the binding media of paintings by thermoanalytical and spectroscopic techniques," Thermochimica Acta, vol. 269-270, pp. 705-727, 1995.

[2] S. Bruni, F. Cariati, F. Casadio, and L. Toniolo, "Spectrochemical characterization by micro-FTIR spectroscopy of blue pigments in different polychrome works of art," Vibrational Spectroscopy, vol. 20, no. 1, pp. 15-25, 1999.

[3] I. M. Bell, R. J. H. Clark, and P. J. Gibbs, "Raman spectroscopic library of natural and synthetic pigments," Spectrochimica Acta A, vol. 53, no. 12, pp. 2159-2179, 1997.

[4] A. Perardi, A. Zoppi, and E. Castellucci, "Micro-Raman spectroscopy for standard and in situ characterisation of painting materials," Journal of Cultural Heritage, vol. 1, supplement 1, pp. S269-S272, 2000.

[5] P. Vandenabeele, H. G. M. Edwards, and L. Moens, "A decade of Raman spectroscopy in art and archaeology," Chemical Reviews, vol. 107, no. 3, pp. 675-686, 2007.

[6] N. Civici, O. Demko, and R. J. H. Clark, "Identification of pigments used on late 17th century Albanian icons by total reflection X-ray fluorescence and Raman microscopy," Journal of Cultural Heritage, vol. 6, no. 2, pp. 157-164, 2005.

[7] D. A. Scott, N. Khandekar, M. R. Schilling, N. Turner, Y. Taniguchi, and H. Khanjian, "Technical examination of a fifteenth-century German illuminated manuscript on paper: a case study in the identification of materials," Studies in Conservation, vol. 46, no. 2, pp. 93-108, 2001.

[8] G. Bitossi, R. Giorgi, M. Mauro, B. Salvadori, and L. Dei, "Spectroscopic techniques in cultural heritage conservation: a survey," Applied Spectroscopy Reviews, vol. 40, no. 3, pp. 187228, 2005.

[9] T. L. Dawson, "Examination, conservation and restoration of painted art," Coloration Technology, vol. 123, no. 5, pp. 281292, 2007.

[10] G. Alessandrini, L. Toniolo, F. Cariati, et al., "A black paint on the facade of a renaissance building in Bergamo, Italy," Studies in Conservation, vol. 41, no. 4, pp. 193-204, 1996.

[11] C. D. Wagner, J. F. Moulder, L. E. David, and W. M. Riggs, Handbook of X-Ray Photoelectron Spectroscopy, Perkin-Elmer, Norwalk, Conn, USA, 1989.

[12] D. Briggs and M. P. Seah, Eds., Practical Surface Analysis, vol. 1, John Wiley \& Sons, New York, NY, USA, 2nd edition, 1993. 

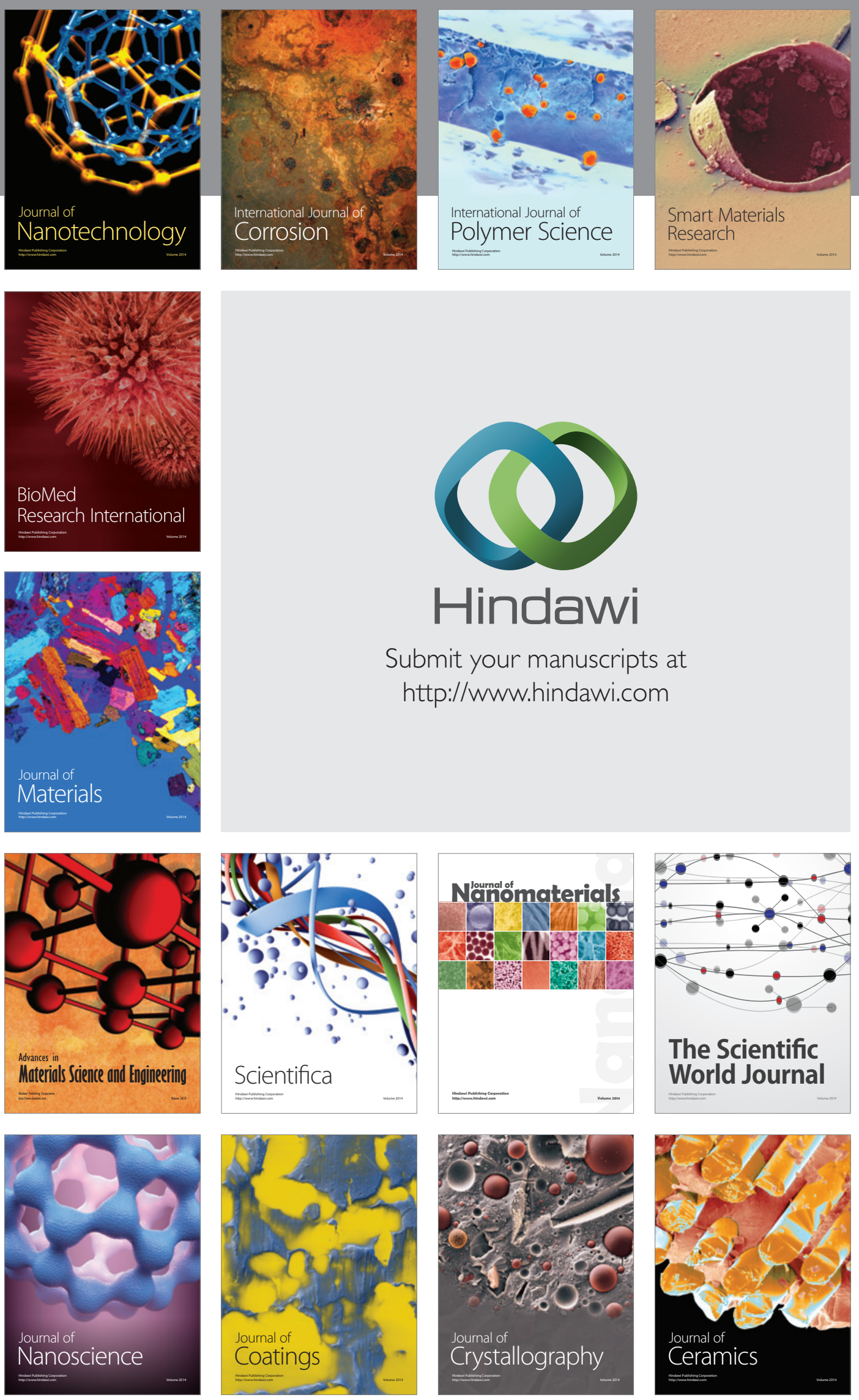

The Scientific World Journal

Submit your manuscripts at

http://www.hindawi.com

\section{World Journal}

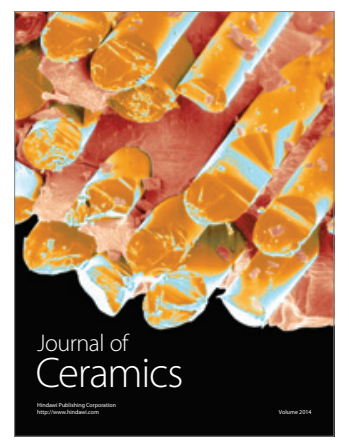

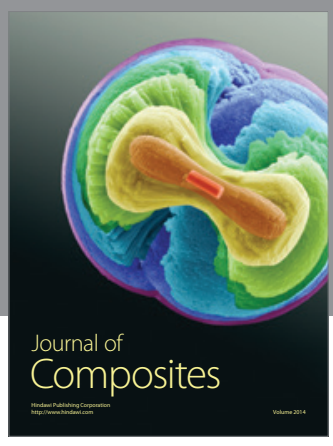
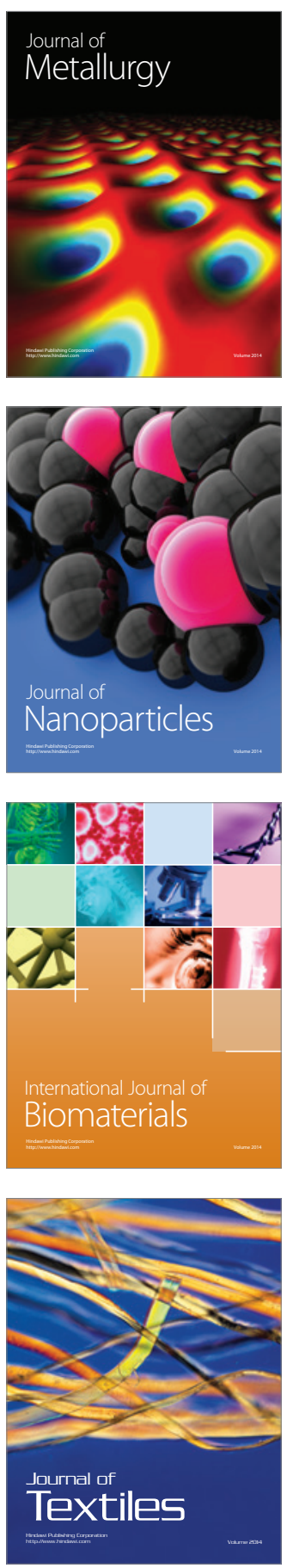